\title{
Particle swarm optimization-based stator resistance observer for speed sensorless induction motor drive
}

\author{
Sang Dang Ho ${ }^{1}$, Petr Palacky ${ }^{2}$, Martin Kuchar ${ }^{3}$, Pavel Brandstetter ${ }^{4}$, Cuong Dinh Tran \\ ${ }^{1,5}$ Faculty of Electrical and Electronics Engineering, Ton Duc Thang University, Vietnam \\ 1,2,3,4,5 Faculty of Electrical Engineering and Computer Science, VSB-Technical University of Ostrava, Czech Republic
}

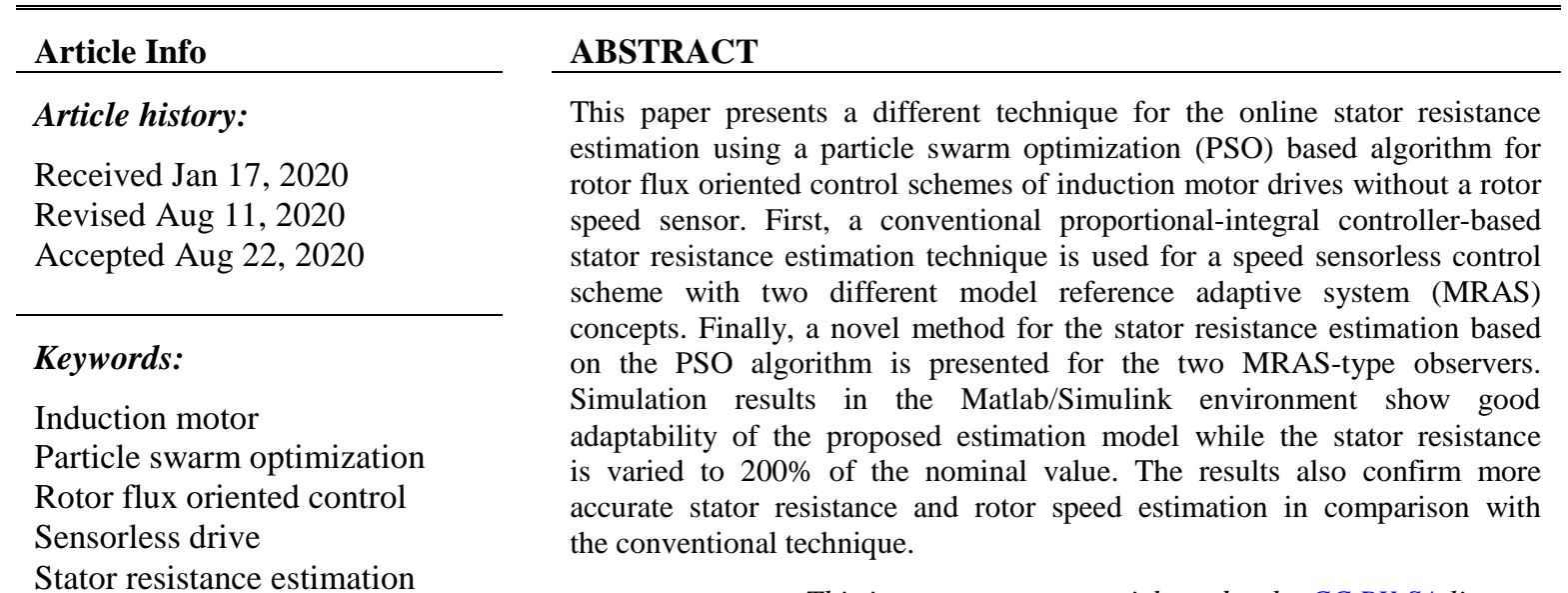

This is an open access article under the CCBY-SA license.

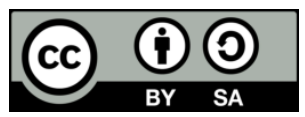

\section{Corresponding Author:}

Martin Kuchar,

Faculty of Electrical Engineering and Computer Science,

VSB-Technical University of Ostrava,

17., listopadu 15/2172, 70833 Ostrava-Poruba, Czech Republic.

Email: martin.kuchar@vsb.cz

\section{INTRODUCTION}

The rotor flux oriented control (RFOC) has been developed and employed widely in an enormous number of industrial applications with induction motors (IM) [1, 2]. Furthermore, numerous speed sensorless control schemes have been applied for the RFOC systems because of recent significant enhancements in the computational power of modern generations of microprocessors. One of the popular techniques is the model reference adaptive system (MRAS) concept, which could provide the correct and stable estimated rotor speed in a wide operating range [3-8]. Nevertheless, both the systems: the RFOC and rotor speed estimation based on the MRAS are so sensitive to the IM parameters, such as the stator and rotor resistance. These parameters are affected by the IM particular operating temperature. The difference between the real and estimated values leads to the unintended operational status and hence, to the poor dynamic performance of the drive. Therefore, the issues of the IM parameters variation and their impact on the performance of IM drives belong to the actual research topics in recent years [5-18].

A review on the subject of the stator and rotor resistances estimation for speed sensorless IM drives is reported in [9]. In [10], a closed-loop stator flux estimator in stator flux oriented control systems assumed that the stator resistance variations caused flux calculation errors. In [11], a MRAS based rotor speed and stator resistance estimator is presented. A first-order adaptive observer is suggested in [12] to estimate the error dynamics, while in [13, 14], an adaptive full-order observer is used. In general, in [10-14], an adaptive reference model with proportional-integral (PI) or integrated controller is proposed. 
In recent years, artificial intelligence (AI) based techniques and soft computing methods such as fuzzy logic (FL) systems, artificial neural networks (ANNs), neural-fuzzy (NF) systems, genetic algorithms (GA), particle swarm optimization (PSO) methods, etc., have been widely used for recognition and control of nonlinear dynamic systems in power electronics and AC drives as presented in [5, 15-29]. Some of these methods are universal function approximators, the others are general-purpose stochastic optimization methods etc. and their application in the field of electrical drives can lead to better performance of electrical drives than conventional control methods. The problem of IM parameters estimation is discussed in [16], where authors proposed a new method which combines ANNs and NF to estimate the stator and rotor resistance simultaneously whilst in [17], only ANNs are used to estimate the stator and rotor resistance for a speed sensorless RFOC system. Similar to [17], authors in [18] also utilizes ANNs for the online estimation of the stator resistance for Direct Torque Control (DTC) of IM drives without a speed sensor.

The PSO algorithm was first introduced by Kennedy and Eberhart in 1995 [21, 22]. It is characterized as simple in concept, easy to implement, and computationally efficient more than many other heuristic techniques. This paper proposes a novel method of the online stator resistance estimation using the PSO algorithm for MRAS based speed sensorless RFOC schemes of IM drives. Concepts in [11, 17, 18] are considered to suggest a simple method concerning the online stator resistance and rotor speed estimation simultaneously. First, to check the correct function of the presented method, two rotor speed observers (rotor flux-based MRAS (RF-MRAS) and current-based MRAS (CB-MRAS) are sequentially applied with a conventional PI-based stator resistance estimator (PI-SRE, described in [11]).

Finally, the proposed technique using the PSO algorithm based stator resistance estimator (PSO-SRE) is also applied with the same conditions as the PI-SRE. Simulation results in the Matlab/Simulink environment confirm a better performance of the PSO-SRE for the RF-MRAS and CB-MRAS observers in comparison with the conventional PI-SRE (see chapter 4 for the simulation results).

\section{CONVENTIONAL MRAS FOR ROTOR SPEED AND STATOR RESISTANCE ESTIMATION}

The block diagrams of the MRAS schemes for the rotor speed and stator resistance estimation are presented in Figures 1 and 2. In these schemes, the conventional PI-based mechanism stator resistance estimator (PI-SRE) with rotor speed estimation mechanisms based on the RF-MRAS and CB-MRAS are sequentially presented. The principle of the RF-MRAS, CB-MRAS, and PI-SRE are discussed in the following subsections.

\subsection{Rotor speed estimation based on RF-MRAS}

As shown in Figure 1, the structure of the RF-MRAS includes two models: the reference (voltage) model uses the stator voltages $\left(u_{S \alpha}, u_{S \beta}\right)$ and stator currents $\left(i_{S \alpha}, i_{S \beta}\right)$ to calculate the components of the rotor flux vector $\left(\psi_{R \alpha}^{V}, \psi_{R \beta}^{V}\right)$ while the adaptive (current) model uses the stator currents and estimated rotor speed $\hat{\omega}_{R}$ to calculate the rotor flux components $\left(\psi_{R \alpha}^{l_{R}}, \psi_{R \beta}^{l}\right)$ too.

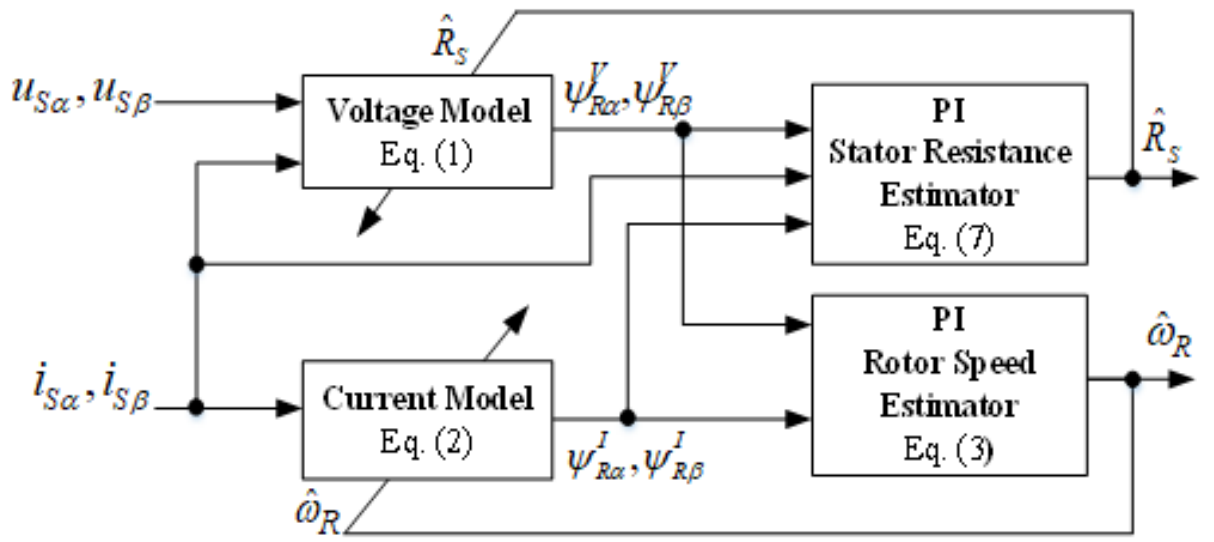

Figure 1. Block diagram of RF-MRAS with PI-SRE

The error of the estimated rotor flux components between these two models $\varepsilon_{\omega}$ is used as an input signal to the PI mechanism for tracking the estimated rotor speed $\hat{\omega_{R}}$, as follows [3]: 


$$
\begin{aligned}
& \psi_{R \alpha}^{V}=\frac{L_{R}}{L_{m}} \int\left(u_{S \alpha}-\hat{R}_{S} i_{S \alpha}\right) d t-\sigma L_{S} i_{S \alpha} \\
& \psi_{R \beta}^{V}=\frac{L_{R}}{L_{m}} \int\left(u_{S \beta}-\hat{R}_{S} i_{S \beta}\right) d t-\sigma L_{S} i_{S \beta} \\
& \psi_{R \alpha}^{I}=\int\left(\frac{L_{m}}{T_{R}} i_{S \alpha}-\frac{1}{T_{R}} \psi_{R \alpha}^{I}-\hat{\omega}_{R} \hat{\psi}_{R \beta}\right) d t \\
& \psi_{R \beta}^{I}=\int\left(\frac{L_{m}}{T_{R}} i_{S \beta}-\frac{1}{T_{R}} \psi_{R \beta}^{I}+\hat{\omega}_{R} \hat{\psi}_{R \alpha}\right) d t \\
& \varepsilon_{\omega}=\psi_{R \alpha}^{I} \psi_{R \beta}^{V}-\psi_{R \beta}^{I} \psi_{R \alpha}^{V} \\
& \hat{\omega}_{R}=K_{P \omega} \varepsilon_{\omega}+K_{I \omega}^{t} \int_{0}^{\varepsilon_{\omega}} d t \\
& K_{P \omega}>0 ; K_{I \omega}>0
\end{aligned}
$$

where

$R_{S}^{\wedge}, R_{R} \quad=$ estimated stator resistance and rotor resistance,

$L_{S}, L_{R} \quad=$ stator and rotor inductance,

$L_{m} \quad=$ mutual inductance,

$T_{R}=L_{R} / R_{R} \quad$ = rotor time constant,

$\sigma=1-L_{m}^{2} /\left(L_{S} L_{R}\right) \quad=$ total leakage factor.

\subsection{Rotor speed estimation based on CB-MRAS}

The CB-MRAS structure for the rotor speed estimation with the stator resistance adaptation is presented in Figure 2.

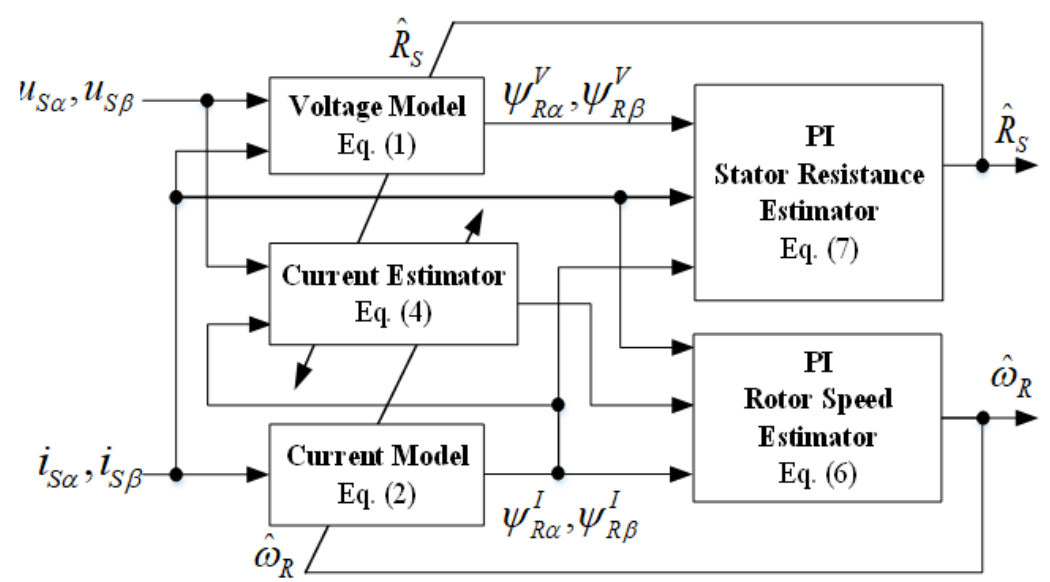

Figure 2. Block diagram of CB-MRAS with PI-SRE

This scheme has one more block for the current estimation and a different adaptive mechanism for the rotor speed estimation compared to the RF-MRAS, as follows [20]:

$$
\begin{aligned}
& \hat{i}_{S \alpha}=\frac{1}{T_{i}} \int\left(K_{1} u_{S \alpha}+K_{2} \psi_{R \alpha}^{I}+K_{3} \hat{\omega}_{R} \psi_{R \beta}^{I}-\hat{i}_{S \alpha}\right) d t \\
& \hat{i}_{S \beta}=\frac{1}{T_{i}} \int\left(K_{1} u_{S \beta}+K_{2} \psi_{R \beta}^{I}-K_{3} \hat{\omega}_{R} \psi_{R \alpha}^{I}-\hat{i}_{S \beta}\right) d t
\end{aligned}
$$


where

$$
K_{1}=\frac{L_{r}}{C_{1} L_{m}}, K_{2}=\frac{L_{m}}{L_{r} R_{S} T_{R}+L_{m}^{2}}, K_{3}=\frac{1}{C_{1}}, C_{1}=\frac{L_{R} \hat{R}_{S}}{L_{m}}+\frac{L_{m}}{T_{R}}, T_{i}=\frac{L_{S} L_{R}-L_{m}^{2}}{C_{1} L_{m}}
$$

and

$$
\begin{aligned}
& \varepsilon_{\omega}=\left(i_{S \alpha}-\hat{i}_{S \alpha}\right) \psi_{R \beta}^{I}-\left(i_{S \beta}-\hat{i}_{S \beta}\right) \psi_{R \alpha}^{I} \\
& \hat{\omega}_{R}=K_{P \omega} \varepsilon_{\omega}+K_{I \omega} \int_{0}^{t} \varepsilon_{\omega} d t
\end{aligned}
$$

\subsection{PI-based mechanism for stator resistance estimator}

The PI-SRE was proposed and evaluated for the stability according to Popov's criterion by the authors in [11]. This block uses the estimated rotor flux components from the voltage $\left(\psi_{R \alpha}^{V}, \psi_{R \beta}^{V}\right)$ and current model $\left(\psi_{R \alpha}^{I}, \psi_{R \beta}^{I}\right)$ to estimate the stator resistance via the error signal $\varepsilon_{R s}$, which is defined as (7) [11]:

$$
\begin{aligned}
& \varepsilon_{R s}=\left(\psi_{R \alpha}^{V}-\psi_{R \alpha}^{I}\right) i_{S \alpha}+\left(\psi_{R \beta}^{V}-\psi_{R \beta}^{I}\right) i_{S \beta} \\
& \hat{R}_{S}=K_{P R s} \varepsilon_{R s}+K_{I R s} \int_{0}^{t} \varepsilon_{R s} d t \\
& K_{P R s}>0 ; K_{I R s}>0
\end{aligned}
$$

\section{PROPOSED STATOR RESISTANCE ESTIMATION BASED ON PSO ALGORITHM}

\subsection{PSO algorithm}

The PSO algorithm is an excellent computational optimization method motivated by the process of hunting food of a flock of birds or fish in the wild [21, 22]. With the advantages such as simplicity, stable convergence and good computational efficiency etc., the PSO has been popularly applied to resolve a large range of optimization problems, such as adaptive tuning of controller gains [23-25], parameters identification [26], loss minimization of electric drive [27]. In the PSO, the bird is called "particle" and constitute a swarm. Each particle indicates a candidate solution to the problem. The particles adjust their positions by travelling through a multidimensional specified searching range. While the journey, each particle adjusts its location according to the previous best position of each individual (called as Pbest) and the global best position (called as Gbest) as shown in Figure 3.

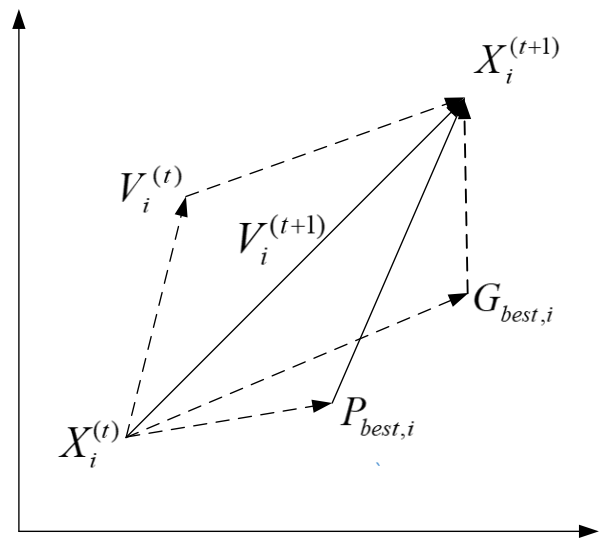

Figure 3. Illustration of adjusting velocity and particle position of PSO algorithm [21]

In each iteration, the modification of velocity and location of each agent can be determined by employing the current speed and the distance from Pbest to Gbest, as presented in the following equations [22]: 


$$
\begin{aligned}
& V_{i}^{(k+1)}=w V_{i}^{(k)}+c_{1} \text { Rand }_{1}\left(\text { Pbest }_{i}-X_{i}^{(k)}\right)+c_{2} \text { Rand }_{2}\left(\text { Gbest }_{i}-X_{i}^{(k)}\right) \\
& X_{i}^{(k+1)}=X_{i}^{(k)}+V_{i}^{(k+1)}
\end{aligned}
$$

where

$i \quad=$ denote each particle,

$k=$ discrete time index,

$X_{i} \quad=$ position of $i^{\text {th }}$ particle,

$V_{i} \quad=$ velocity of $i^{\text {th }}$ particle,

$w \quad=$ inertia function,

$c_{1,2}=$ acceleration constants (self-confidence),

Rand $_{1,2}=$ a random number on an interval $[0,1]$,

Pbest $_{i}=$ best position found by $i^{\text {th }}$ particle (personal best),

Gbest $_{i}=$ best position found by swarm (global best).

In Figure 4, the major steps in the procedure of the PSO are described as follows [21]:

Step1: Generate a population of particles with random locations and velocities in $\mathrm{d}$ dimensions of the problem space within the allowable range.

Step 2: Evaluate the objective function of each particle in the swarm. If the current value is better than the previous Pbest, then Pbest is replaced by the current value. If the best value of Pbest is better than the previous Gbest, the Gbest value is replaced by the best value, and the location of a particle with the best value is stored.

Step 3: Modify the searching point of each particle according to (8).

Step 4: The loop terminating condition is checked to determine if it has been achieved (based on objective function values or number of interaction), if not satisfied, then the process is repeated from step 2. Otherwise, the algorithm is stopped.

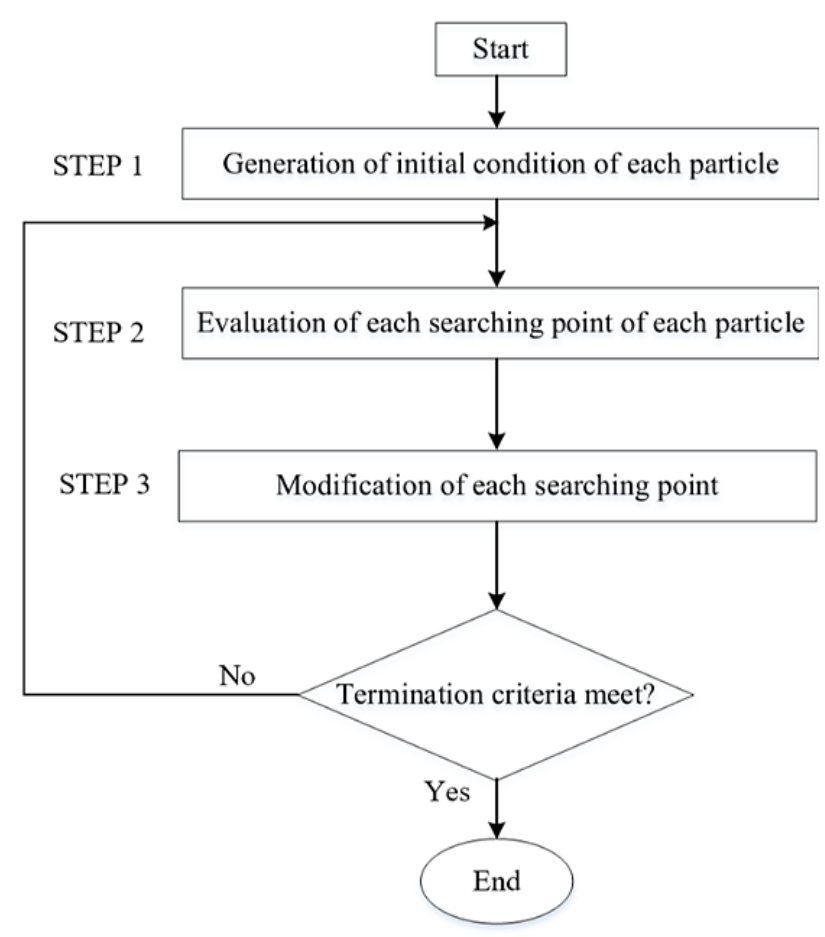

Figure 4. Steps in PSO algorithm

\subsection{PSO-based stator resistance estimation mechanism}

In this research, the PSO-SRE as shown in Figure 5 is suggested to replace the PI-SRE, and its principle is discussed below. Equations (1) and (2) from section 2 can be rewritten as: 


$$
\begin{aligned}
& \frac{d \psi_{R \alpha}^{V}}{d t}=\frac{L_{R}}{L_{m}}\left(u_{S \alpha}-\hat{R}_{S} i_{S \alpha}-\sigma L_{S} \frac{d i_{S \alpha}}{d t}\right) \\
& \frac{d \psi_{R \beta}^{V}}{d t}=\frac{L_{R}}{L_{m}}\left(u_{S \beta}-\hat{R}_{S} i_{S \beta}-\sigma L_{S} \frac{d i_{S \beta}}{d t}\right) \\
& \frac{d \psi_{R \alpha}^{I}}{d t}=\frac{1}{T_{R}}\left(L_{m} i_{S \alpha}-\psi_{R \alpha}^{I}-\hat{\omega}_{R} T_{R} \psi_{R \beta}^{I}\right) \\
& \frac{d \psi_{R \beta}^{I}}{d t}=\frac{1}{T_{R}}\left(L_{m} i_{S \beta}-\psi_{R \beta}^{I}+\hat{\omega}_{R} T_{R} \psi_{R \alpha}^{I}\right)
\end{aligned}
$$

Assuming that the obtained rotor flux components from the voltage and current model are equal. From (9) and (10), the following equations can be obtained:

$$
\begin{aligned}
& \sigma L_{S} \frac{d i_{S \alpha}}{d t}=u_{S \alpha}-\hat{R}_{S} i_{S \alpha}-\frac{L_{m}^{2}}{L_{R} T_{R}} i_{S \alpha}+\frac{L_{m}}{L_{R} T_{R}} \psi_{R \alpha}^{I}+\frac{L_{m}}{L_{R}} \hat{\omega}_{R} \psi_{R \beta}^{I} \\
& \sigma L_{S} \frac{d i_{S \beta}}{d t}=u_{S \beta}-\hat{R}_{S} i_{S \beta}-\frac{L_{m}^{2}}{L_{R} T_{R}} i_{S \alpha}+\frac{L_{m}}{L_{R} T_{R}} \psi_{R \beta}^{I}-\frac{L_{m}}{L_{R}} \hat{\omega}_{R} \psi_{R \alpha}^{I}
\end{aligned}
$$

Transformation of (11) to a discrete type is defined as:

$$
\hat{i}_{S \alpha}(k)=B_{1} \psi_{R \alpha}^{I}(k-1)+B_{2} \psi_{R \beta}^{I}(k-1)+B_{3} u_{S \alpha}(k-1)+B_{4} \hat{i}_{S \alpha}(k-1)
$$

where

$$
\begin{aligned}
& B_{1}=\left[T_{S} /\left(\sigma L_{S}\right)\right]\left[L_{m} /\left(L_{R} T_{R}\right)\right] \\
& B_{2}=\left[T_{S} /\left(\sigma L_{S}\right)\right]\left[\left(L_{m} / L_{R}\right) \hat{\omega}_{R}\right] \\
& B_{3}=T_{S} /\left(\sigma L_{S}\right) \\
& B_{4}=\left[1-\left(T_{S} / \sigma L_{S}\right) \hat{R}_{S}-\left(T_{S} / \sigma L_{S}\right)\left(L_{m}^{2} /\left(L_{R} T_{R}\right)\right)\right]
\end{aligned}
$$

Equation (14) shows how to estimate the stator current while the stator resistance is variable. The weights $B_{1}, B_{2}, B_{3}$ are directly computed from the rotor speed, motor parameters, and sampling time. All motor parameters are assumed to remain unchanged during the operational conditions except the stator resistance.

The error function of the current $i_{S \alpha}$ is given:

$$
E_{\alpha}=\frac{1}{2} \varepsilon_{\alpha}^{2}=\frac{1}{2}\left(i_{S \alpha}(k)-\hat{i}_{S \alpha}(k)\right)^{2}
$$

Similarly, transformation of (12) to a discrete type is defined as:

$$
\begin{aligned}
& \hat{i}_{S \beta}(k)=B_{1} \psi_{R \beta}^{I}(k-1)-B_{2} \psi_{R \alpha}^{I}(k-1)+B_{3} u_{S \beta}(k-1)+B_{4} \hat{i}_{S \beta}(k-1) \\
& E_{\beta}=\frac{1}{2} \varepsilon_{\beta}^{2}=\frac{1}{2}\left(i_{S \beta}(k)-\hat{i}_{S \beta}(k)\right)^{2}
\end{aligned}
$$

With the proposed PSO algorithm, the $R_{S}$ value of $B_{4}$ weight will be searched so that the fitness function $F$ is minimized:

$$
F=E_{\alpha}+E_{\beta}
$$


The procedure of the PSO algorithm for the stator resistance estimation as shown in Figure 5 is also based on the same procedure as described in the previous subsection 3.1, see Figure 4, including the steps as follows:

- Formulate the initial population and initial position randomly of each particle $\left(R_{S}\right)$ in a range of the searching space (from 0.5 to 2.5 of the nominal stator resistance value).

- Calculate the fitness function of each particle using (13) to (18).

- Find the individual best of each particle.

- Find the global best in the entire population.

- Update the velocity and position of each particle according to (8).

- Repeat step 2 to step 5 until the criterion is satisfied.

- Apply the optimized stator resistance value to the system.

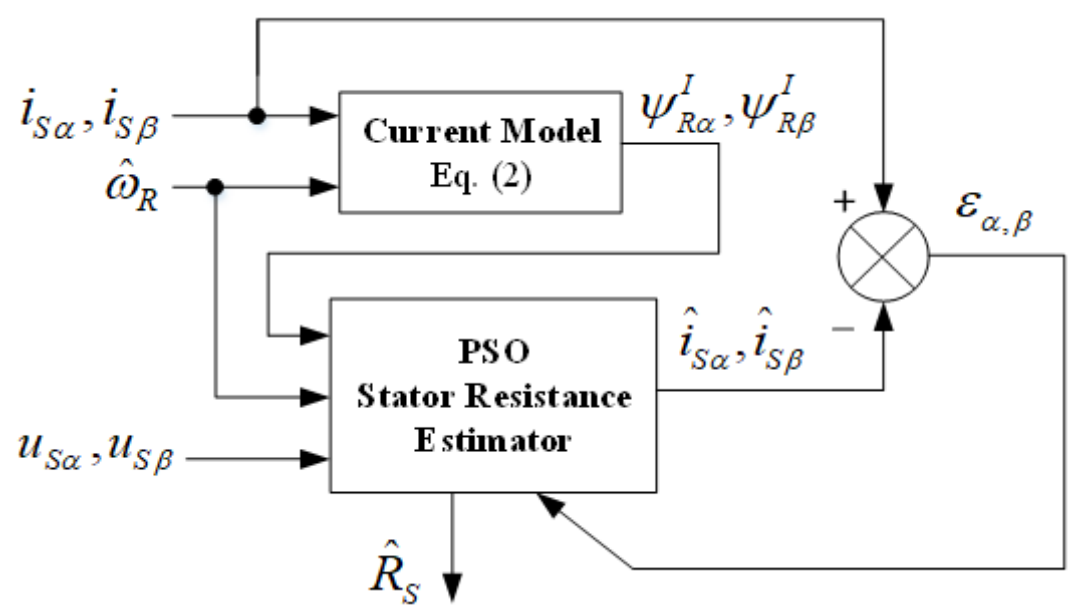

Figure 5. Structure of PSO-based stator resistance estimator

\section{SIMULATION RESULTS}

The proposed algorithm is implemented in the Matlab/Simulink environment to obtain the simulation results. The mentioned techniques for the online stator resistance estimation (PI-SRE and PSO-SRE) are sequentially tested with the speed sensorless control schemes (RF-MRAS and CB-MRAS) for the RFOC system of the IM drive according to a block diagram shown in Figure 6 (see in appendix).

The simulation is carried out on a three-phase squirrel cage IM, whose parameters are given in Table 1. Figure 7(a) illustrates the ratio of step changes of the stator resistance, and the references of the rotor speed and load torque are shown in Figure 7(b). In Figure 8, the ratio between the estimated and actual values of the stator resistance using the PI-SRE and PSO-SRE for the RF-MRAS are presented, respectively. Similarly, Figure 9 displays the PI-SRE and PSO-SRE for the CB-MRAS. Figures 10 and 11 shows the errors of the actual and estimated rotor speed of the two MRAS-type observers when using the PI-SRE and PSO-SRE, sequentially. The results of the rotor speed and motor torque responds are shown in Figures 12 and 13 for the PI/PSO-SRE and the RF/CB-MRAS, respectively.

Table 1. Parameters of induction motor

\begin{tabular}{clc}
\hline Symbol & \multicolumn{1}{c}{ Quantity } & Values \\
\hline$P_{n}$ & rated power & $3.3 \mathrm{~kW}$ \\
$V_{n}$ & rated voltage & $380 \mathrm{~V}$ \\
$R_{S}$ & stator resistance & $4.179 \Omega$ \\
$L_{S}$ & stator inductance & $0.209 \mathrm{H}$ \\
$R_{R}$ & rotor resistance & $2.118 \Omega$ \\
$L_{R}$ & rotor inductance & $0.209 \mathrm{H}$ \\
$L_{m}$ & mutual inductance & $0.192 \mathrm{H}$ \\
$p$ & pole pair number & 2 \\
$J$ & moment of inertia & $0,047 \mathrm{~kg} \cdot \mathrm{m}^{2}$ \\
\hline
\end{tabular}




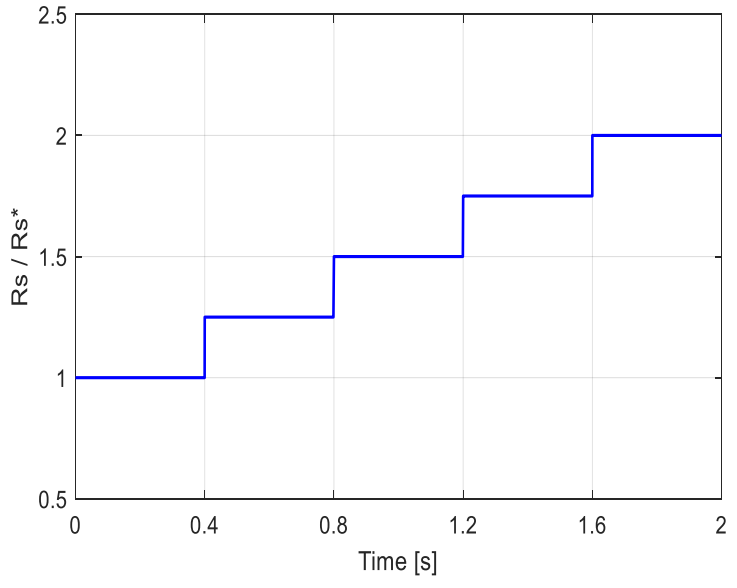

(a)

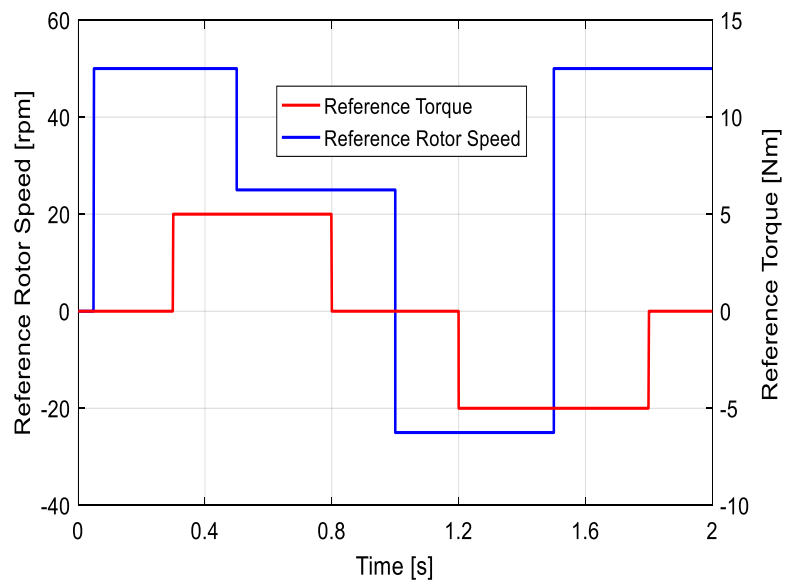

(b)

Figure 7. (a) Illustration of variation ratio between changed and nominal stator resistance,

(b) References of rotor speed and load torque

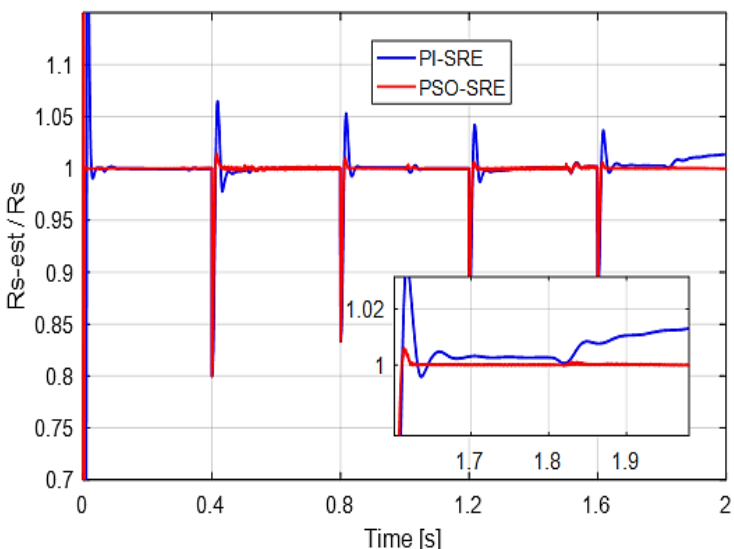

Figure 8. Ratio of estimated and actual values of stator resistance for RF-MRAS with PI-SRE and PSO-SRE

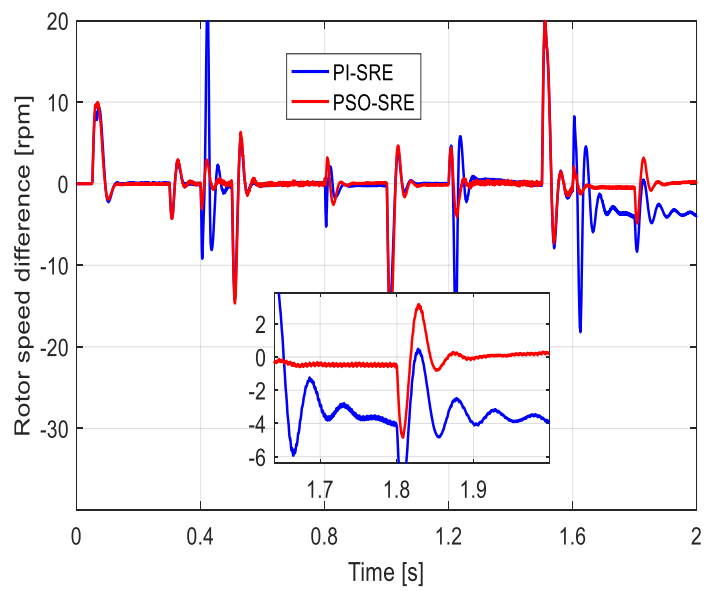

Figure 10. Error of actual and estimated rotor speed for RF-MRAS with PI-SRE and PSO-SRE

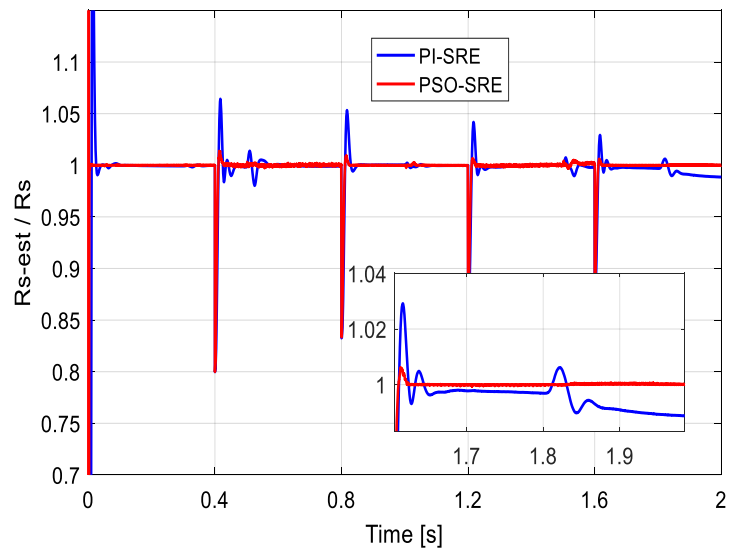

Figure 9. Ratio of estimated and actual values of stator resistance for CB-MRAS with PI-SRE and PSO-SRE

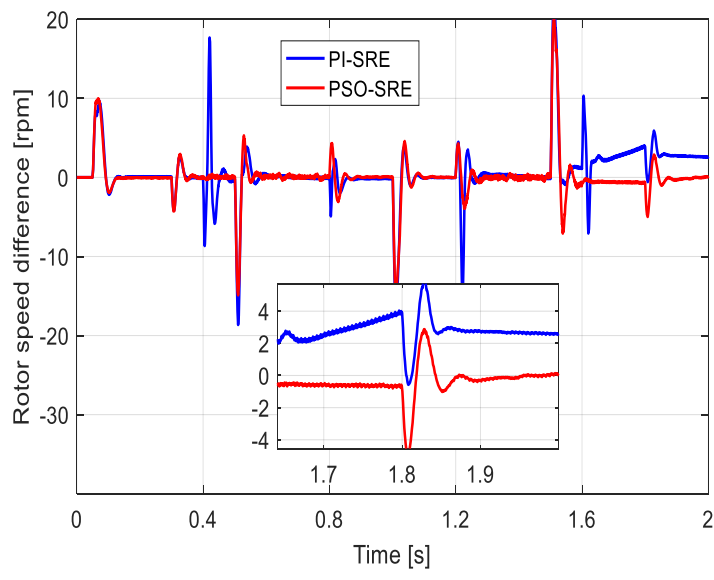

Figure 11. Error of actual and estimated rotor speed for CB-MRAS with PI-SRE and PSO-SRE 


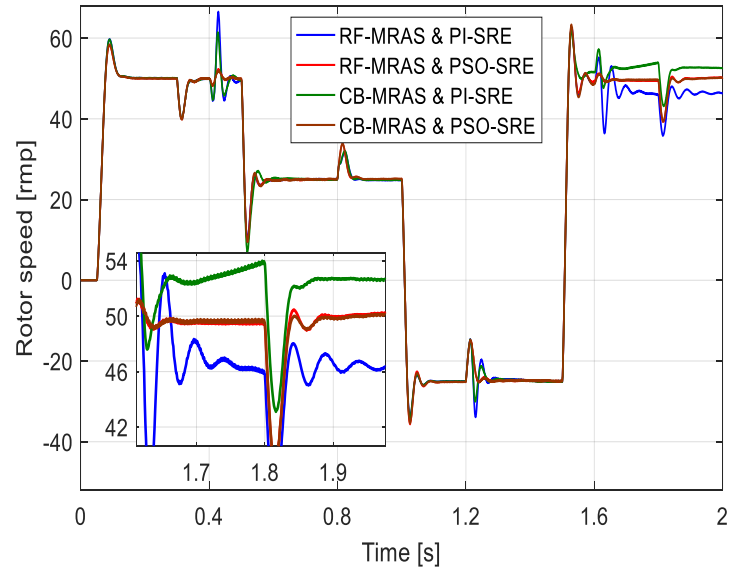

Figure 12. Rotor speed responds of RF-MRAS and CB-MRAS using PI-SRE and PSO-SRE

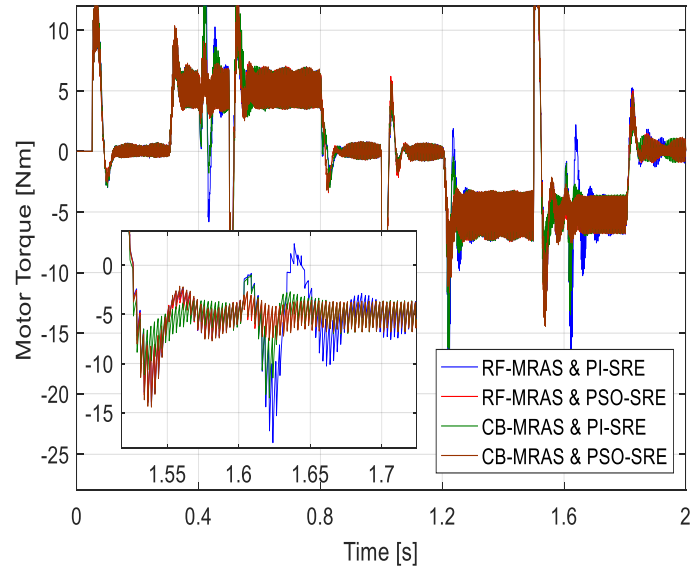

Figure 13. Motor torque responds of RF-MRAS and CB-MRAS using PI-SRE and PSO-SRE

To show more clearly the performance of the above mentioned estimators, we apply the Integral of the time weighted absolute error (ITAE) criterion (defined by (19)) to evaluate the error between the estimated and real value of the stator resistance (ESR), rotor speed difference (RSD), and the error between the reference and real motor torque (EMT). These factors are presented in Table 2.

$$
\operatorname{ITAE}=\int_{0}^{\infty} t|e(t)| d t
$$

where $t$ is the time and $e(t)$ is the difference between a set point and controlled variable.

As shown in Figure 8 and 9 and the first row in Table 2, it indicates that the proposed PSO-SRE gives more accurate and stable responses of the stator resistance estimation than the conventional PI-SRE does. Each time the stator resistance has a step change (at $t=0.4 ; 0.8 ; 1.2 ; 1.6 \mathrm{~s}$, see Figure 7 a)), as well as the rotor speed and torque changes as shown in Figure $7 \mathrm{~b}$ ), the PSO-SRE oscillates slightly for a very short time and stabilizes quickly with excellent tracking, even when the stator resistance increases twice the original value. Meanwhile, the PI-SRE gives more overshoots, fluctuation, and worse responsive tracking, especially during $200 \%$ of the nominal stator resistance (at $t=1.6$ to $2 \mathrm{~s}$ ).

Figures 10, 11 and the second row in Table 2 also prove the advantages in the rotor speed estimation of the both MRAS when operate with the proposed PSO-SRE. The RSD values obtained from the two MRAS-type observers with the PSO-SRE are smaller than those from the PI-SRE. The overshoot and oscillation of the RF/CB-MRAS with the PSO-SRE are always smaller and still keep the correct response in the wide range of the stator resistance values.

The EMT values provided by the both MRAS-type observers with the PI/PSO-SRE (the third row of Table 2) are almost equal, but the RF/CB-MRAS schemes using the PSO-SRE give better responses and smoother rotor speed and motor torque than those of the PI-SRE as shown in Figures 12 and 13.

Table 2. Comparisons of RF/CB-MRAS with PI/PSO-SRE

\begin{tabular}{ccccc}
\hline ITAE & $\begin{array}{c}\text { RF-MRAS } \\
\text { with PI-SRE }\end{array}$ & $\begin{array}{c}\text { RF-MRAS } \\
\text { with PSO-SRE }\end{array}$ & $\begin{array}{c}\text { CB-MRAS } \\
\text { with PI-SRE }\end{array}$ & $\begin{array}{c}\text { CB-MRAS } \\
\text { with PSO-SRE }\end{array}$ \\
\hline ESR $\left(\times 10^{-2}\right)$ & 9.01 & $\mathbf{2 . 8 7}$ & 8.54 & 2.91 \\
RSD & 4.834 & 2.111 & 3.937 & $\mathbf{2 . 1 0 5}$ \\
EMT & 3.274 & 2.773 & 2.849 & $\mathbf{2 . 7 4 6}$ \\
\hline
\end{tabular}

\section{CONCLUSION}

This study introduces a novel technique concerning the online estimation of the stator resistance using the PSO algorithm applied to the MRAS based speed sensorless RFOC of IM drives. The simulation results confirm that the proposed method is able to identify variations of the stator resistance and converge to a steady-state and stable value when the stator resistance increases to $200 \%$ of the nominal value. The proposed technique also shows the excellent dynamic respond of the rotor speed and stator resistance estimation in comparison with the conventional PI based mechanism. 


\section{APPENDIX}

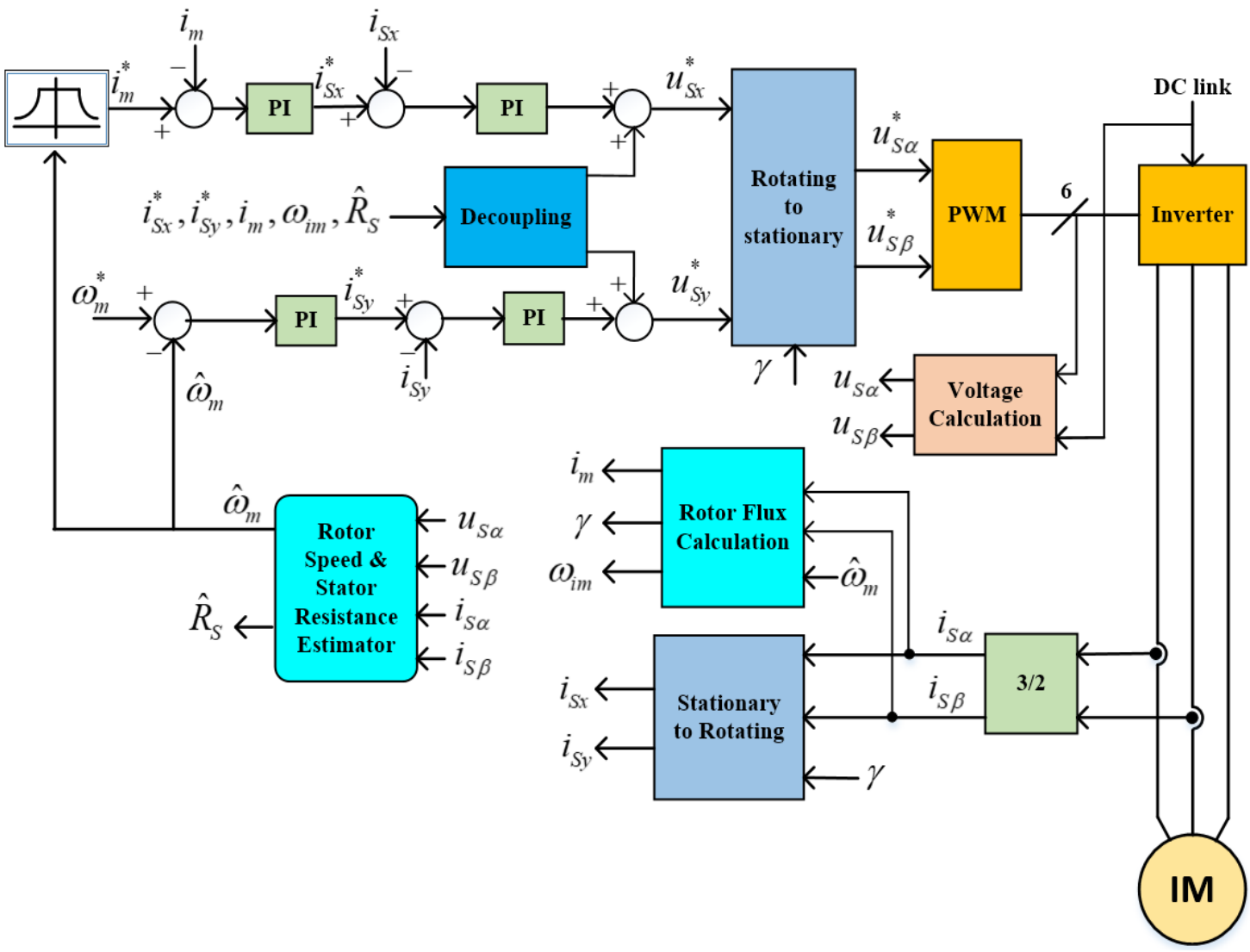

Figure 6. Block diagram of MRAS based sensorless RFOC of IM drive with SRE

\section{ACKNOWLEDGEMENTS}

This work was supported by Project reg. no. SP2020/128-Student Grant Competition of VSBTechnical University of Ostrava, 2020.

\section{REFERENCES}

[1] P. Vas, "Vector control of AC machines," Clarendon Press, Oxford, 1990.

[2] E. Levi, "High Performance Drives," Course notes, Liverpool John Moores University, 2002.

[3] P. Vas, "Sensorless Vector Control and Direct Torque Control," Oxford Univ. Press, UK, 1990.

[4] P. Brandstetter, "Sensorless Control of Induction Motor Using Modified MRAS," International Review of Electrical Engineering (IREE), vol. 7, no. 3, pp. 4404-4411, 2012.

[5] P. Vas, "Artificial-intelligence-based electrical machines and drives," Oxford Science Publication, 1999.

[6] M. Rashed and A. F. Stronach, "A stable back-EMF MRAS-based sensorless low-speed induction motor drive insensitive to stator resistance variation," IEE Proceedings-Electric Power App., vol. 151, no. 6, pp. 685-693, 2004.

[7] C. Lascu, et al., "Comparative study of adaptive and inherently sensorless observers for variable-speed inductionmotor drives," IEEE Transactions on Industrial Electronics, vol. 53, no. 1, pp. 57-65, 2006.

[8] E. Zerdali and E. C. Mengüç, "Novel Complex-Valued Stator Current-Based MRAS Estimators With Different Adaptation Mechanisms," IEEE Transactions on Instrumentation and Measurement, vol. 68, no. 10, 2019.

[9] J. Chen and J. Huang, "Stable simultaneous stator and rotor resistances identification for speed sensorless induction motor drives: Review and new results," IEEE Transactions on Power Electronics, vol. 33, no. 10, pp. 8695-8709, 2018.

[10] E.D. Mitronikas, et al., "A new stator resistance tuning method for stator-flux-oriented vector-controlled induction motor drive," IEEE Transactions on Industrial Electronics, vol. 48, no. 6, pp. 1148-1157, 2001.

[11] V. Vasic, et al., "A stator resistance estimation scheme for speed sensorless rotor flux oriented induction motor drives," IEEE Transactions on Energy Conversion, vol. 18, no. 4, pp. 476-483, 2003.

[12] J. Chen, et al., "Resistances and speed estimation in sensorless induction motor drives using a model with known regressors," IEEE Transactions on Industrial Electronics, vol. 66, no. 4, pp. 2659-2667, 2018. 
[13] M. S. Zaky, "Stability analysis of speed and stator resistance estimators for sensorless induction motor drives," IEEE Transactions on Industrial Electronics, vol. 59, no. 2, pp. 858-870, 2012.

[14] M. S. Zaky and M. K. Metwaly, "Sensorless torque/speed control of induction motor drives at zero and low frequencies with stator and rotor resistance estimations," IEEE Journal of Emerging and Selected Topics in Power Electronics, vol. 4, no. 4, pp. 1416-1429, 2016.

[15] J. M. Gutierrez-Villalobos, et al., "A review of parameter estimators and controllers for induction motors based on artificial neural networks," Neurocomputing, vol. 118, pp. 87-100, 2013.

[16] B. Karanayil, et al., "Stator and rotor resistance observers for induction motor drive using fuzzy logic and artificial neural networks," IEEE Transactions on Energy Conversion, vol. 20, no. 4, pp. 771-780, 2005.

[17] B. Karanayil, et al., "Online stator and rotor resistance estimation scheme using artificial neural networks for vector controlled speed sensorless induction motor drive," IEEE Transactions on Industrial Electronics, vol. 54, no. 1, pp. 167-176, 2007.

[18] H. H. Vo, et al., "Speed Estimators Using Stator Resistance Adaption for Sensorless Induction Motor Drive," Advances In Electrical And Electronic Engineering (AEEE), vol. 14, no. 3, pp. 267-273, 2016.

[19] D. Perdukova and P. Fedor, "A Model-Based Fuzzy Control of an Induction Motor," Advances in Electrical and Electronic Engineering, vol. 12, no. 5, pp. 427-434, 2014.

[20] T. Orłowska-Kowalska and M. Dybkowski, "Stator-current-based MRAS estimator for a wide range speed-sensorless induction-motor drive," IEEE Transactions on Industrial Electronics, vol. 57, no. 4, pp. 1296-1308, 2009.

[21] J. Kennedy and R. Eberhart, "Particle swarm optimization," Proc. of the IEEE International Conference on Neural Networks, Perth, WA, Australia, pp. 1942-1948, 1995.

[22] Y. Shi and R. Eberhart, "A modified particle swarm optimizer," Proc. of the IEEE International Conference on Evolutionary Computation, pp. 69-73, 1998.

[23] T. Banerjee, et al., "Off-line optimization of PI and PID controller for a vector controlled induction motor drive using PSO," Proc. of International Conference on Electrical \& Computer Engineering, pp. 74-77, 2010.

[24] A. A. A. El-Gammal and A. A. El-Samahy, "A modified design of PID controller for DC motor drives using Particle Swarm Optimization PSO," Proc. of International Conference on Power Engineering, Energy and Electrical Drives, pp. 419-424, 2009.

[25] A. Ramya, M. Balaji and V. Kamaraj, "Adaptive MF tuned fuzzy logic speed controller for BLDC motor drive using ANN and PSO technique," The Journal of Engineering, vol. 2019, no. 17, pp. 3947-3950, 2019.

[26] E. M. Tofighi, A. Mahdizadeh and M. R. Feyzi, "Online estimation of induction motor parameters using a modified particle swarm optimization technique," IECON 2013-39th Annual Conference of the IEEE Industrial Electronics Society, pp. 3645-3650, 2013.

[27] M. Sreejeth, M. Singh and P. Kumar, "Efficiency enhancement for indirect vector-controlled induction motor drive," International Journal of Electronics, vol. 106, no. 9, pp. 1281-1294, 2019.

[28] R. Mini, P. Shabana Backer, H. Satheesh, M. N. Dinesh, "Low speed estimation of sensorless DTC induction motor drive using MRAS with neuro fuzzy adaptive controller," International Journal of Electrical and Computer Engineering (IJECE), vol. 8, no. 5, pp. 2691-2702, 2018.

[29] M. Rekha, M. K. Kumar, "Variable frequency drive optimization using torque ripple control and self-tuning PI controller with PSO," International Journal of Electrical and Computer Engineering (IJECE), vol. 9, no. 2, pp. 802-814, 2019.

\section{BIOGRAPHIES OF AUTHORS}

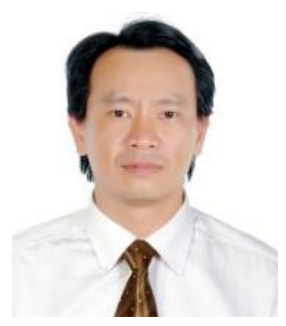

S. D. Ho was born in Ho Chi Minh City, Vietnam in 1973. He received the B.S. and M.S. degrees in Electrical Engineering from Ho Chi Minh University of Technology, Ho Chi Minh City, Vietnam in 2001 and 2008, respectively. Presently, he is working as a lecturer at the Faculty of Electrical and Electronics Engineering, Ton Duc Thang University, Ho Chi Minh City, Vietnam. He is currently pursuing the Ph.D. degree in electrical engineering at VSBTechnical University of Ostrava, Czech Republic. His research interests involve the optimization of the power system and applications of soft computing in control of electric machine drives.

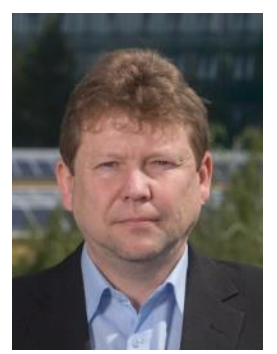

P. Palacky was born in Novy Jicin, Czech Republic, in 1970. He received the M.Sc. and Ph.D. degrees in Electrical Engineering from VSB-Technical University of Ostrava, Czech Republic, in 1993 and 2000, respectively. He is currently an Associate Professor in Electrical Machines, Apparatus and Drives and head of department of Electronics, Faculty of Electrical Engineering and Computer Science at VSB-Technical University of Ostrava. Research activities include microcomputer control systems, modern control methods of A.C. drives and machine parameters identifications. 

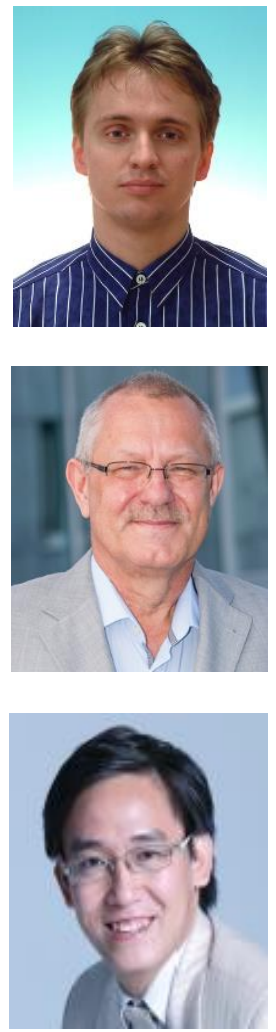

M. Kuchar was born in Ostrava, Czech Republic, in 1977. He received the M.Sc. and Ph.D. degrees in Electrical Engineering from VSB-Technical University of Ostrava, Czech Republic, in 2000 and 2003, respectively. He is currently an Associate Professor in Electrical Engineering in the Department of Electronics, Faculty of Electrical Engineering and Computer Science, VSBTechnical University of Ostrava. His research interests include DSC based control systems, sensorless and sensor fault tolerant control of AC drives, applications of observers, estimators and soft computing methods in the control of electrical drives.

P. Brandstetter was born in Ostrava, Czech Republic, 1955, 1 June. He received the M.Sc. and Ph.D. degrees in Electrical Engineering from Brno University of Technology, Czech Republic, in 1979 and 1987, respectively. He is currently a full professor in Electrical Machines, Apparatus and Drives and dean of Faculty of Electrical Engineering and Computer Science at VSBTechnical University of Ostrava. Research activities include modern control methods of A.C. drives, for example, sensorless control of the IM and PMSM drives using different types of the observers.

C. D. Tran was born in Ho Chi Minh, Vietnam. He graduated from the University of Technology, Ho Chi Minh City, Viet Nam and received his B.E. and M.E. degrees in electrical electronics power engineering in 2005 and 2008, respectively. Now, he is teaching at the department of electrical and electronics engineering, Ton Duc Thang University, Ho Chi Minh City, Vietnam. He is currently pursuing the Ph.D. degree in electrical engineering at VSBTechnical University of Ostrava, Czech Republic. His research interests include modern control methods of electrical drives, automatic control system, intelligent control system, operation and control power system. 